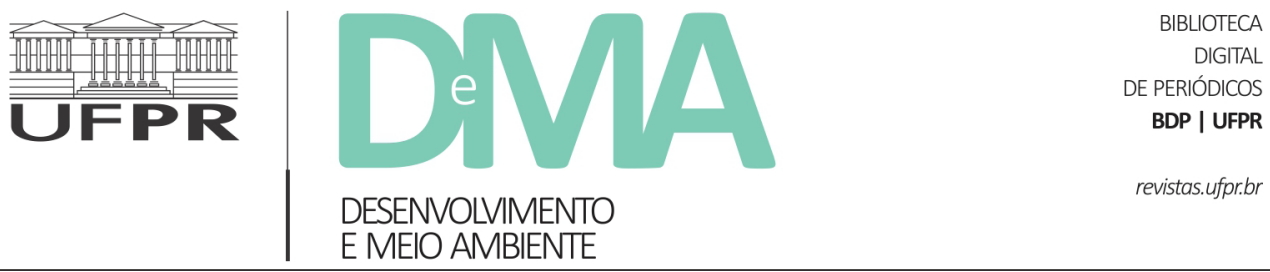

\title{
A trajetória de encerramento do maior lixão da América Latina: entre centralização, descentralização e exclusão
}

\section{The closure trajectory of the largest dumping ground in Latin America: between centralization, decentralization and exclusion}

\author{
Mauro Guilherme Maidana CAPELARI ${ }^{1 *}$, Mariana Rodrigues Amaral DOMICIANO ${ }^{2}$, Lucia de Fatima \\ Nascimento de QUEIROZ ${ }^{3}$, Ludmilla Ferreira BANDEIRA ${ }^{4}$, Fabiano TONI ${ }^{1}$ \\ ${ }^{1}$ Centro de Desenvolvimento Sustentável, Universidade de Brasília (UnB), Brasília, DF, Brasil. \\ ${ }^{2}$ Gestão de Políticas Públicas, Universidade de Brasília (UnB), Brasília, DF, Brasil \\ ${ }^{3}$ Ministério da Economia, Brasília, DF, Brasil \\ ${ }^{4}$ Ministério do Desenvolvimento Regional, Brasília, DF, Brasil. \\ *E-mail de contato: capelari.unb@gmail.com
}

Artigo recebido em 8 de outubro de 2019, versão final aceita em 23 de maio de 2020, publicado em 2 de setembro de 2020.

RESUMO: $\quad$ O maior lixão a céu aberto da América Latina foi fechado em 2018 após mais de uma década de embate. Nós analisamos a trajetória do fechamento do lixão (2010 a 2018) à luz da literatura sobre implementação e participação em políticas públicas. Realizamos entrevistas e coletas documentais. Os resultados apontaram para dois momentos distintos do processo de implementação da política: o da descentralização (2010 a 2014 ) e o da centralização (2014 a 2018). Enquanto no primeiro momento houve autonomia na tomada de decisão dos atores envolvidos, num movimento de construção de diversos núcleos independentes e com capacidade deliberativa, no segundo período, esses núcleos foram descaracterizados, e o processo de decisão foi estruturado de forma a concentrar as ações na figura do governador. Ao mesmo tempo em que houve diferenças nos dois períodos analisados, em ambos observamos a exclusão dos catadores na tomada de decisão. Assim, mesmo que o fechamento do Lixão tenha sido considerado bem-sucedido, a falta de participação dos catadores nos processos decisórios gerou uma situação socioeconômica desfavorável para eles, que perderam suas precárias atividades econômicas dependentes dos resíduos sólidos recicláveis e não conseguiram se reposicionar profissionalmente em curto prazo.

Palavras-chave: catadores; reciclagem; resíduos sólidos; Brasília/DF. 
ABSTRACT: The largest open-air dump in Latin America was closed in 2018 after more than a decade of conflicts. We analyzed the trajectory of the dump closure (2010 to 2018) in light of the literature on implementation and participation in public policies. We conducted interviews and collected documents . The results pointed to two distinct moments in the policy implementation process: decentralization (2010 to 2014) and centralization (2014 to 2018). While Iin the first moment there was autonomy in the decision making of the actors involved in a movement of construction of several independent nuclei with deliberative capacity, in the second period, these nuclei were uncharacterized, and the decision process was structured in order to concentrate the actions in the figure of the governor. . At the same time that there were differences in the two periods analyzed, in both we observed the exclusion of the collectors in decision making. Therefore, even if the closure of the garbage dump was considered successful, the lack of participation of the collectors in decision-making processes generated an unfavorable socioeconomic situation for them, who lost their precarious economic activities dependent on recyclable solid waste and were unable to reposition themselves professionally in the short term.

Keywords: waste pickers; recycling; solid waste; Brasília/DF.

\section{Introdução}

A construção do maior lixão a céu aberto da América Latina (Campos, 2018) - Lixão da Estrutural - confunde-se com a história de construção de Brasília/DF. Desde que a planejada capital nacional foi inaugurada, na década de 1960 , a região do Setor Complementar de Indústria e Abastecimento (SCIA) foi escolhida para abrigar os rejeitos produzidos pelos moradores da nova cidade. Com uma área de 201 hectares, a 20 quilômetros da Esplanada dos Ministérios, o lixão chegou a receber, em seu período de maior movimento, 3 mil toneladas de resíduos sólidos diários (SLU, 2016).

A movimentação era tamanha que um bairro inteiro surgiu ao seu redor. Nomeado de Estrutural, o bairro possuía, em 2019, uma população aproximada de 40 mil habitantes, e muitos de seus moradores ainda sobreviviam economicamente da relação com o seu vizinho, o lixo. Devido à pouca valorização da atividade de coleta e seleção de resíduos sólidos recicláveis, o bairro passou a figurar entre os que possuem menor renda per capita de
Brasília, situado em um local carente em infraestrutura básica, educação, saúde e cultura (SLU, 2016).

Para além de atrair uma população de baixa renda e uma comunidade com diversas privações, o Lixão da Estrutural, induzido pelo aumento populacional de Brasília (Correio Braziliense, 2017), passou a ser objeto de debate sobre a produção de riscos socioambientais para a população de todo o Distrito Federal. Tais riscos apresentavam-se por meio da debilidade à saúde humana, mortes de trabalhadores por falta de equipamentos de segurança, contaminação dos lençóis freáticos e bacias hidrográficas, emissão de gás metano, impacto territorial e ambiental ao Parque Nacional de Brasília, dentre outros (ADASA, 2017).

Nesse ambiente de riscos socioambientais, desde a década de 1980 houve movimentos direcionados ao fechamento ou à transferência de parte dos resíduos sólidos produzidos na região para outros locais do Distrito Federal. Um importante empecilho para o fechamento do Lixão, contudo, estava nos altos valores de recuperação da área degradada, uma vez que custava mais do que a construção de um aterro sanitário. Foi nesse contexto que houve 
a manutenção das atividades do Lixão por mais de sessenta anos (Metrópoles, 2019).

O movimento de permanência das atividades do Lixão da Estrutural foi rompido, ou ao menos, tensionado, com a promulgação da Política Nacional de Resíduos Sólidos (Lei 12.305/2010) (Brasil, 2010), que criou metas para os municípios eliminarem seus lixões, especialmente a partir da consolidação de consórcios públicos. Essa regulação estatal fez com que os movimentos de encerramento da atividade do Lixão da Estrutural se tornassem mais intensos e o tema se consolidasse na agenda do governo distrital. A despeito da complexidade e da morosidade do processo de encerramento, problemas igualmente percebidos em outros municípios brasileiros (ABRELPE, 2017), ele se concretizou em 2018.

Nesse sentido, discutiremos a trajetória de fechamento do Lixão da Estrutural entre os anos de 2010 e 2018, o que envolveu a análise de dois planos de intervenção e a operacionalização desses planos por parte de dois governos distritais. A partir da literatura de implementação e participação, pretendemos responder às seguintes perguntas: como os planos de intervenção foram implementados pelos governos distritais? Qual foi o grau de participação dos catadores na execução desses planos?

Esse trabalho divide-se em seis seções após esta introdução. Na segunda e na terceira, apresentaremos a literatura sobre implementação e participação em políticas públicas. Na quarta seção, apresentaremos a metodologia do trabalho. Nas seções cinco e seis, apresentaremos e discutiremos os resultados e destacaremos as categorias descentralização, centralização e exclusão, assim como as implicações dessas características na trajetória de encerramento do Lixão. Por fim, a sétima seção trará as considerações finais do trabalho.

\section{Implementação de políticas públicas}

A expressão implementação de políticas públicas tem sido relacionada tanto à ação de executar algo, mediante providências concretas, quanto associada à fase de execução das decisões adotadas na etapa de formulação das políticas públicas (Pressman \& Wildavsky, 1984; Lotta, 2019a). As variáveis envolvidas em processos de implementação de políticas públicas têm poder explicativo para evidenciar as razões pelas quais as intenções que guiam a formulação de uma determinada política nem sempre se traduzem em ações governamentais. Assim, estudos de implementação requerem análises que sejam não apenas capazes de identificar como as ações relativas a uma determinada política pública se relacionam às suas próprias ações, mas que contemplem variáveis existentes no contexto geral de implementação (Pressman \& Wildavsky, 1984; Marulanda et al., 2007).

Nesse sentido, os estudos de implementação estão interessados em compreender as desconformidades entre os objetivos estipulados e os resultados que foram alcançados por determinada política pública, assim como as determinantes que justificariam tais desconformidades (Lotta, 2019b).

Há, na literatura, um longo debate sobre o estilo adequado e propício de coordenar os recursos, as estruturas e os atores em prol de alcançar resultados mais próximos do que foi planejado na etapa de formulação das políticas (Pires, 2009; Lima \& D’Ascenzi, 2013; Lotta, 2019a). Frequentemente, essa discussão está atrelada ao entendimento pro- 
cessual e prospectivo de pensar na natureza e no contexto do problema (Wu et al., 2018), na estrutura normativa que propicia clareza e discernimento ao policy maker (Mazmanian \& Sabatier, 1989), na inerente complexidade e conflito que subjaz à implementação (Weible \& Sabatier, 2017); no perfil e na discricionariedade dos burocratas (Tummers, 2017; Lipszky, 2010); nos instrumentos de implementação (Lascoumes \& Les Gales, 2012) ou mesmo na capacidade estatal para a execução de políticas (Evans, 2014; Pires \& Gomide, 2014; Margetts \& Hood, 2012).

Os estudos sobre implementação enfatizam alguns recortes analíticos que os diferenciam na busca pela discrepância do planejamento em comparação com o que foi executado. O primeiro recorte busca compreender o perfil do burocrata e suas ações individuais e coletivas como elementos centrais na explicação das práticas de implementação. $\mathrm{O}$ segundo espectro analítico tem como interesse compreender os motivos pelos quais os burocratas agem de maneira distinta. Nesse momento, a variável dependente é o comportamento dos burocratas. $\mathrm{O}$ terceiro espectro analítico busca compreender como diferentes práticas da burocracia levam a distintos resultados. Nesse arranjo, a variável dependente é o resultado da implementação e suas variantes, enquanto as variáveis independentes são as diferentes práticas, comportamentos e interações dos burocratas (Lotta, 2019b). Esse último espectro é que o presente trabalho enfatiza.

Não menos importante para o debate sobre a implementação de políticas públicas são as abordagens "top-down" e "bottom-up" que caracterizaram a direção dos fluxos de implementação após a década de 1970 (Sabatier, 1986; Birkland, 2015).
Os trabalhos dedicados à abordagem "top-down" distinguiram-se na literatura ao pesquisar fatores que condicionam os resultados da implementação de uma determinada política. Os resultados dessas pesquisas têm proporcionado a elaboração de um conjunto de suposições, consideradas ideais para a garantia da implementação, dentre as quais se destacam: (i) metas claramente definidas para mensurar o desempenho; (ii) um conjunto de ferramentas demarcadas para o cumprimento de metas; (iii) fluxos de implementação, pensados através de cadeia lógico-causal, que proporcionariam o sequenciamento das etapas; (iv) formuladores com amplo reconhecimento da capacidade e do comprometimento dos implementadores (Birkland, 2015; Lotta, 2019a).

$\mathrm{Na}$ abordagem top-down, a preocupação do policy maker é criar as estruturas e os controles adequados para garantir a conformidade com as metas e os objetivos previamente estabelecidos. As falhas de implementação são superáveis a partir do reenquadramento das práticas às normas previamente estabelecidas. Ainda que seja considerado como efetivo e eficiente, o processo de implementação top-down apresenta limitações no que diz respeito às dificuldades de transmissão dos objetivos tratados e do engajamento de atores para a implementação desses objetivos. Isso ocorre porque tais atores podem não ter participado nem tampouco ter sido ouvidos na delimitação do problema e na elaboração dos objetivos (Sabatier, 1986; Birkland, 2015).

Diametralmente oposta é a abordagem bottom-up, na qual é prevista a inclusão de habilidades e motivações dos implementadores de nível hierárquico inferior, ao mesmo tempo em que a política é desenhada a partir do rastreamento das ideias e dos interesses iniciais das estruturas governamentais 
locais. Apenas depois de concluídos estes processos, coletam-se as propostas dos níveis mais altos da hierarquia de governo. Há, nessa percepção, a ideia de que os objetivos são ambíguos e não suficientemente explícitos, fato que normalmente levaria a conflitos de interesses entre os policy makers (Lotta, 2019a).

Assim, a abordagem bottom-up não busca a conformidade, mas, sobretudo, procura reduzir os conflitos inerentes ao processo de implementação, com o propósito de tornar mais realista o seu entendimento e proporcionar a escolha mais adequada de ferramentas. Ainda que a falta de foco em um objetivo específico seja a crítica mais reproduzida sobre essa abordagem, seus pontos positivos prevalecem ao proporcionarem à implementação uma visão de rede de atores trabalhando em conjunto e reduzindo a resistência a uma dada política (Sabatier, 1986; Birkland, 2015).

Em síntese, a revisão da literatura sobre a implementação de políticas públicas apresentou ao longo de sua história elaborações teórico-conceituais que colocam em evidência o papel que pode ser assumido pelos estados, no que concerne ao seu aparato legal, político-decisório e burocrático. Essas elaborações sugerem que análises sobre o exercício das responsabilidades na implementação de políticas requerem a adoção de variáveis que contribuam para a compreensão sobre como ocorrem as decisões governamentais e sobre como os dirigentes e os distintos setores e burocratas da administração pública têm atuado para assegurar o cumprimento dessas responsabilidades e sua aderência com o processo de formulação da política.

Desde 2010, com a promulgação da Política Nacional de Resíduos Sólidos (Brasil, 2010), há um esforço de parte da comunidade acadêmica e de gestores públicos em analisar sua implementação, seja em nível nacional (IPEA, 2012; Besen et al., 2017; Maiello et al., 2018), seja em nível subnacional (Moraes, 2012; Heber \& Silva, 2014; Campos, 2018).

\section{Participação: uma revisão em contexto nacional}

Os processos participativos na história recente da relação entre o Estado e a sociedade civil têm como marco as revoluções Americana e Francesa (Canovan, 2006). Para Chambers \& Kopstein (2006), há seis formas de relação entre a sociedade civil e o estado: 1) de independência, 2) de oposição, 3) de apoio, 4) de diálogo, 5) de parceria e 6) de relação globalizante. Segundo esses autores, a relação de diálogo, forma escolhida como base teórica deste trabalho, se estabelece quando o Estado entende a importância da sociedade civil para a melhoria de qualidade do processo decisório e dos resultados da política pública (formulação e implementação) e cria canais de comunicação e de prestação de contas. A relação dialógica prevê, em adição, o empoderamento do cidadão que passa a ter maior consciência de seus direitos assim como maior capacidade de reivindicação e de concretização de seus interesses. Nesse sentido, diversos trabalhos desenvolveram-se na área de participação sustentando, por um lado, a característica positiva de empoderamento da sociedade (Dagnino, 2002; Evans, 2002; Coelho \& Favareto, 2010; Gaventa \& Barrett, 2010; Abers \& Bulow, 2019) e, por outro lado, a característica de melhoria dos processos políticos e resultados das políticas públicas (Ribot, 2007; Avritzer, 2019). 
A participação dialógica, nesse sentido, contribui para o desenvolvimento de capacidades locais em detrimento de monoculturas institucionais (Evans, 2003) e colabora para a melhoria na qualidade e para a celeridade da resolução de problemas públicos, por permitir o envolvimento de atores, do conhecimento e das institucionalidades locais. Desse modo, os ganhos dos processos participativos dialógicos ocorreriam tanto no resultado da política quanto na qualidade da democracia e dos aspectos cíveis (Evans, 2003), motivo de sua escolha como aporte teórico.

A definição de participação dialógica de Chambers \& Kopstein (2006) implica a capacidade do cidadão de influenciar as ações do Estado por meio de mecanismos que o tornem agente do processo de tomada de decisão e que avancem para além das práticas tradicionais de participação representativa pelo voto. Ela inclui o empoderamento contínuo do cidadão, uma vez que ele se encontra envolvido, usualmente, com os problemas públicos em seu entorno. Sua caracterização, portanto, está ligada à frequência, à forma e ao discernimento do cidadão em relação ao seu espaço para participação e influência nas ações do Estado (Nogueira, 2011).

A participação dialógica é materializada a partir de casos práticos ocorridos no cotidiano da democracia brasileira. Como exemplo, podem ser citados: (i) os casos de implementação do orçamento participativo em Porto Alegre e em Belo Horizonte com suas formas de gestão democrática; (ii) os conselhos gestores que preveem a participação de atores da sociedade civil no processo de tomada de decisão em políticas públicas; (iii) os fóruns constituídos para realizar pressão e assessorar comunidades locais; (iv) as organizações da sociedade civil e não governamentais em suas práticas de capitanear recursos públicos e internacionais e aplicá-los em iniciativas locais em comum acordo com a sociedade e o próprio Estado; e (v) a economia solidária e sua autogestão na produção, distribuição e consumo de produtos econômicos (Abers \& Bulow, 2019; Avritzer, 2019).

No Brasil, houve momentos de participação da sociedade civil na primeira metade do século XX em atividades historicamente entendidas de competência exclusiva do Estado. Com a chegada do período militar, a sociedade civil passou a ser desconsiderada no processo de tomada de decisão, o que sacramentou a separação entre esses dois atores. A Constituição de 1988 (Brasil, 2016), por sua vez, demarcou o momento de retomada da união entre os pares (Silva, 2019), ainda que de forma não completamente ajustada, uma vez que não havia, e ainda não há, um entendimento político, econômico e social sobre os termos de responsabilidade, de poder e de atuação de cada um deles. O que se tem atualmente, entretanto, é o reconhecimento da importância democrática e de construção de cidadania a partir de uma sociedade civil ativa e propositiva (Teixeira et al., 2019) que busca novas práticas e institucionalidades (Nogueira, 2014) com intuito de transformar a relação entre Estado e sociedade civil em ambientes mais digitais e menos analógicos (Abranches, 2017).

Na política ambiental brasileira e, de maneira mais estrita, na política de resíduos sólidos (Azevedo \& Gomes, 2018), a participação da sociedade civil no processo político concretizou-se a partir de três ondas: científica e nacionalista (1950-1970), contestatória (1970-1990) e propositiva (1990 em diante). Todas elas, com maior ou menor intensidade, influenciaram a formação legal e organizacional 
da política ambiental brasileira ao longo da história (Hochstetler \& Keck, 2007).

A primeira onda foi constituída por projetos pontuais e nacionalistas, quase sem conexão com movimentos de fora do Brasil. A proposta da primeira onda era alertar para o uso descontrolado dos recursos naturais e a necessidade de haver um planejamento para a sustentação a longo prazo das atividades econômicas nacionais, próximo a um caráter utilitarista da natureza (Padilha, 2010). O movimento foi composto por burocratas estatais advindos das primeiras instituições ambientais criadas no Brasil, com destaque para Paulo Nogueira Neto, Maria Tereza Pádua e Alceo Magnanini. Teve uma característica estritamente científica, em que ciência era entendida como o principal elemento para influenciar a produção da política ambiental (Viola, 1987; Urban, 2001; Hochstetler \& Keck, 2007). A segunda, denominada de contestatória (1970-1990), teve características de protesto e de movimentos ativistas. Ganhou perfil combativo ao se opor ao regime militar e às suas políticas de grandes obras, especialmente hidrelétricas e nucleares. Nesse período, as ONG's começam a ser criadas mais intensamente e difundidas pelo Brasil num movimento "from protest to engagement" (Hochstetler \& Keck, 2007).

A terceira onda, nomeada de propositiva (1990 em diante), possui como característica principal a profissionalização e a provisão de serviços, lobby e difusão de informações. A sociedade civil possui como objetivo central colaborar com o Estado para resolver problemas coletivos. A frase que resume a forma de atuação da sociedade civil nesse período é: from protest to project, numa clara alusão sobre o papel a ser desempenhado pelos movimentos ambientais (Hochstetler \& Keck, 2007).
A sedimentação dessas ondas foi acompanhada da presença de rotinas de interação que se instalaram ao longo do movimento ambiental brasileiro (Abers \& Bulow, 2019). Uma destas rotinas é a participação institucionalizada em que há a aproximação da sociedade civil com o Estado a partir da abertura do próprio Estado para tais interações. Iniciada no período de redemocratização, a participação institucionalizada apresentou-se por meio de fóruns, conselhos, audiências públicas, conferências, dentre outros. Presente não só na política ambiental, a participação institucionalizada desenvolveu-se ao longo dos últimos trinta anos com a aproximação do movimento ambiental e do Estado, na direção de melhoria democrática e aperfeiçoamento das políticas públicas numa relação dialógica.

É com base nesta discussão sobre os processos participativos e políticos que faremos a análise sobre a participação dos catadores no movimento de fechamento do Lixão da Estrutural, num diálogo próximo com outros trabalhos que se empenharam no mesmo tema (Bortoli, 2009; Bringhenti \& Gunther, 2011; Jacobi \& Besen, 201; Lima et al., 2017). Argumentaremos sobre a exclusão desses atores e as implicações que isso lhes trouxe, assim como as implicações à legitimação da política de encerramento do Lixão.

\section{Metodologia}

A pesquisa foi conduzida sob uma abordagem qualitativa (Denzin \& Lincoln, 2017) e de estudo de caso (Gerring, 2017). O caso analisado foi o Lixão da Estrutural, localizado em Brasília/DF, em seu processo de fechamento iniciado em 2010 e finalizado em 2018. 
A obtenção dos dados se deu principalmente por meio de pesquisa documental aprofundada, especialmente pela coleta e análise de relatórios governamentais, de planos de governos e de documentos oficiais, tomados entre os anos de 2017 e 2018. Isso foi complementado por três entrevistas semiestruturadas, realizadas com profissionais do governo do Distrito Federal que estiveram diretamente envolvidos com o caso estudado durante todo o recorte temporal analisado. As entrevistas foram utilizadas tanto para esclarecer algumas dúvidas e lacunas remanescentes da análise documental quan- to para validar nossas conclusões preliminares. $\mathrm{O}$ critério de saturação (Yin, 2017) foi um indicativo de que entrevistas adicionais seriam desnecessárias.

Os dados coletados foram de fontes documentais e entrevistas semiestruturadas (Tabela 1).

As técnicas de análise de conteúdo e de triangulação dos dados foram utilizadas na interpretação e na construção das categorias (Yin, 2017).

A análise foi centrada no conteúdo das entrevistas e na operacionalização dos Planos Distritais de Intervenção e nos programas de inclusão dos catadores de materiais recicláveis em atividades

TABELA 1 - Fontes documentais e perfil dos entrevistados da pesquisa.

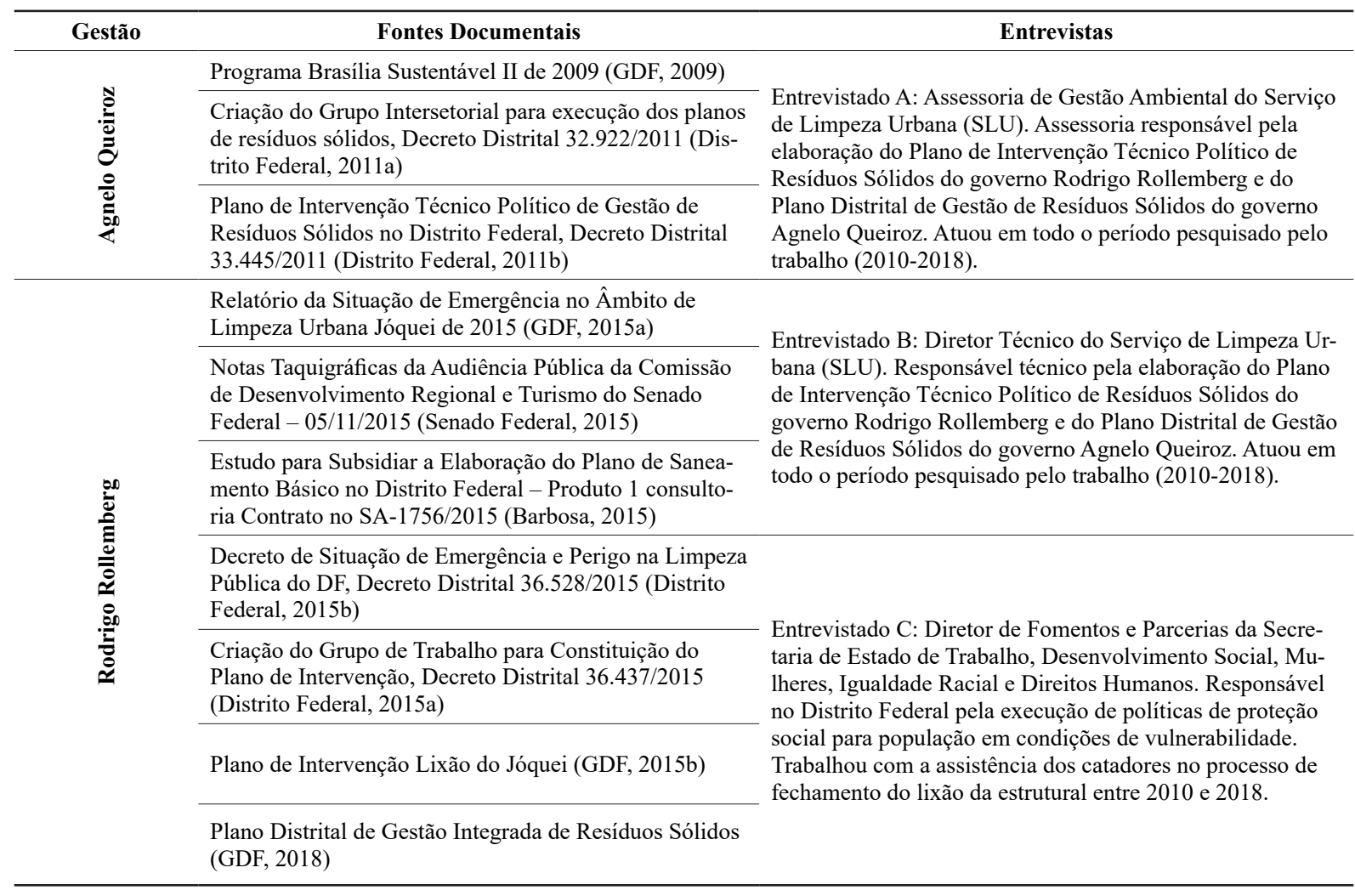

FONTE: Elaboração Própria (2019). 
socioeconômicas. Ainda na fase de exploração do material, foi possível perceber as tendências e os aspectos mais importantes e de maior valor na implementação da política em questão. Assim, as categorias centralização, descentralização e exclusão foram construídas a partir da análise dos dados coletados.

\section{Resultados e discussão}

Com o objetivo de analisar como ocorreu a trajetória de fechamento do "Lixão da Estrutural", este trabalho enfatizou três categorias que emergiram das análises documentais e das entrevistas: centralização, descentralização e exclusão. Em adição, o marco temporal estabelecido envolveu a gestão dos governos distritais de Agnelo Queiroz (2011-2015) e Rodrigo Rollemberg (2015-2018), governos que tomaram posse posteriormente à publicação da Política Nacional de Resíduos Sólidos (Brasil, 2010).

\subsection{Da descentralização à centralização}

O governo de Agnelo Queiroz produziu sua primeira ação relacionada à tentativa de fechamento do Lixão da Estrutural em 2011, logo nos primeiros meses de mandato, ao assinar o Decreto 32.922/2011 (Distrito Federal, 2011a). O ponto central do Decreto foi a criação do Comitê Intersetorial de Resíduos Sólidos - CIRS, que visava demarcar as competências, as responsabilidades e os arranjos de coordenação e de cooperação para a implementação da Política Nacional de Resíduos Sólidos (Brasil, 2010) no Distrito Federal e dos componentes do Programa Brasília Sustentável II (GDF, 2009). Tais arranjos estavam sendo direcionados a partir de uma estrutura de gestão integrada e consorciada no âmbito do Distrito Federal e entorno. O CIRS foi composto de 11 (onze) entidades públicas do Distrito Federal, dentre elas, Secretarias e órgãos executores, sendo a Secretaria de Estado de Governo do Distrito Federal a responsável por coordenar as demais instituições participantes. Não havia, nessa ocasião, entidades de fora do governo (Distrito Federal, 2011a).

Em um prazo de 30 (trinta) dias, a partir dos trabalhos desenvolvidos no âmbito da CIRS, o governo publicou o Decreto 33.445/2011 (Distrito Federal, 2011b), que aprovava o Plano de Intervenção Técnico Político de Gestão de Resíduos Sólidos no Distrito Federal e a gestão integrada de resíduos na capital. Estavam previstas no Plano seis ações estruturantes para a gestão dos resíduos sólidos, dentre as quais se destacaram as ações de reestruturação da infraestrutura de coleta e o tratamento e destinação final dos resíduos sólidos. Ambas abordavam diretamente o fechamento do Lixão da Estrutural (Distrito Federal, 2011b).

A estrutura proposta pelo governador para cumprir as determinações do Decreto 33.445/2011 (Distrito Federal, 2011b) distribuiu as funções previstas no Plano para os atores que compunham o CIRS. Nesse sentido, a ação estruturante que enfatizava o fechamento do Lixão ficou a cargo do Serviço de Limpeza Urbana - SLU. Esse órgão foi o ator principal das tentativas de fechamento do Lixão nessa gestão. A partir de sua coordenação foram percebidos avanços nos trâmites das licenças prévias para o início da operação do novo aterro sanitário, o planejamento para as áreas de triagem dos resíduos sólidos, de transbordo e de recicla- 
gem. Foram previstas áreas destinadas a descartes de resíduos de construção e demolição, elaborado o programa de coleta seletiva nas residências do Distrito Federal, além do planejamento de três novos pontos para a construção de aterros sanitários na capital, como forma de não mais centralizar os impactos ambientais negativos em um único espaço territorial. Houve ainda a produção de relatórios e diagnósticos sobre a situação dos resíduos sólidos em Brasília (Domiciano et al., 2019).

Apesar de a SLU atuar como órgão coordenador e, portanto, responsável pelos processos de fechamento do Lixão, o que se percebeu foi a limitação dessa entidade em dar respostas concretas ao problema dos resíduos sólidos em Brasília. As metas previstas no Decreto 33.445/2011 (Distrito Federal, 2011b) pouco avançaram nos anos de 2012 a 2014; as evidências apontaram para a falta de poder da SLU, que não conseguia deliberar devido à ausência intrínseca de autoridade perante outros órgãos participantes do processo de encerramento do Lixão:

No governo Agnelo realizamos várias leis, vários decretos, várias questões, o plano e intervenção foi publicado e já previa o fechamento do lixão, o aterro sanitário, área de resíduos da construção civil, galpão para catador. Só que para viabilizar não foi fácil não...". Ainda, "o Agnelo descentralizou isso para o SLU fazer sozinho. A Agência reguladora das Águas, Energia e Saneamento - ADASA e a Secretaria de Desenvolvimento Social e Transferência de RendaSEDEST trabalhavam juntas com a SLU, mas não era prioridade dos chefes destes dois órgãos ofechamento do Lixão, assim como era prioridade para o chefe da SLU (Entrevistado B, p. 3).

A coordenação institucional produzida entre Secretarias ou órgãos de mesmo nível hierárquico gerou animosidade entre os mesmos, deixando o processo de negociação e de tomada de decisão prejudicado. "No governo Agnelo Queiroz, as Secretarias ficaram com a função de fazer a deliberação para o fechamento do Lixão. A articulação existia entre os órgãos, mas cabia a cada um deles deliberar para atender as suas demandas" (Entrevistado C). Tal situação foi contraproducente em termos de atingir resultados comuns, uma vez que incentivou a corrida individual das Secretarias/órgãos para atender as agendas específicas de suas pastas. Isso retardou o alcance dos resultados gerando um cenário "Dom Quixote" (Entrevistado B), em que o idealismo passou a assumir as narrativas oficiais, enquanto o realismo apresentava resultados pouco otimistas.

Nesse sentido, fez-se presente um cenário descentralizador de tomada de decisão dentro do governo Agnelo Queiroz para o processo de implementação de estratégias para o fechamento do Lixão da Estrutural. Essa descentralização e, de certa forma, autonomia decisória, gerou poucos resultados concretos na medida em que proporcionou uma corrida individualizada de cada órgão em defesa de sua própria agenda de resíduos sólidos, diminuindo os momentos de cooperação e de atuação conjunta por um tema comum. Apesar de não existir evidências sobre algum tipo de conflito entre órgãos governamentais, a implementação por meio da proposta bottom-up não trouxe elementos claros que justificassem o trabalho em conjunto dos atores policy makers, a não ser pela natureza e contexto do problema (Wu et al., 2018). Nesse sentido, a gestão de Agnelo, que finalizou em janeiro de 2015, não conseguiu implementar as metas estabelecidas pelo Decreto 33.445/2011 (Distrito Federal, 2011b). 
A implementação bottom-up proposta por Agnelo sofreu por falta de coordenação, problema apontado em outros casos empíricos sobre implementação da Política Nacional de Resíduos Sólidos (Heber \& Silva, 2014; Besen et al., 2017; Maiello et al., 2018). Ao mesmo tempo em que prometeu autonomia para agências estatais, não conseguiu organizar as atividades de cada uma delas para que pudessem, em conjunto, alcançar objetivos comuns. A falta de coordenação é um dos principais problemas presentes em implementação de políticas do tipo bottom-up (Souza, 2018), uma vez que necessita de esforços do agente coordenador que normalmente estão relacionados ao aumento de custos financeiros e de tempo nos processos políticos. Diversos tipos de incentivos, seletivos ou não, são estudados como forma racional de sensibilizar os atores políticos às ações cooperativas (Axelrod \& Hamilton, 1981; Olson, 2009; Ostrom, 2014), mas nenhum deles foi evidenciado no conteúdo das respostas dos entrevistados, tampouco nos documentos analisados. Notadamente, a gestão Agnelo não apresentou elementos suficientes para uma coordenação efetiva do processo de encerramento do Lixão, o que inviabilizou a conclusão no período de sua gestão.

Com a eleição para governador, o sucessor de Agnelo Queiroz foi Rodrigo Rollemberg, que permaneceu no cargo até janeiro de 2019. Nos primeiros meses de mandato, Rollemberg publicou o Decreto 36.528/2015 (Distrito Federal, 2015b), que declarava situação de emergência e de perigo no âmbito de limpeza pública em Brasília. O Decreto foi motivado pelo relatório publicado pelo SLU e intitulado "Relatório da Situação de Emergência no Âmbito de Limpeza Urbana Jóquei" (GDF, 2015a) e pelos casos de acidentes fatais e incêndios no Lixão que chamaram a atenção da mídia (Portal G1, 2014). Paralelamente, um novo Decreto, 36.437/2015 (Distrito Federal, 2015a), foi expedido pelo governador para elaborar e executar um plano de intervenção no Lixão da Estrutural. Por meio desse mesmo Decreto foi criado um grupo de trabalho que seria o responsável pela produção do plano de intervenção, elaborado no final do mesmo ano (GDF, 2015b). Tal grupo, assim como no governo de Agnelo, privilegiou atores governamentais e deu preferência para as Secretarias de Governo, num total de 17 Secretarias. Em um momento posterior, o Instituto de Estudos Socioeconômicos - INESC, organização não governamental, foi contratado pelo Governo Distrital para apoio nas políticas voltadas aos catadores.

O modelo operacional do plano, produzido pelo grupo de trabalho no âmbito do Decreto 36.437/2015 (Distrito Federal, 2015a), apresentou estratégias mais objetivas em relação ao Plano produzido no governo anterior. Além do fechamento do Lixão da Estrutural, previa ações para a política de resíduos no Distrito Federal e entorno. O plano de Rollemberg apresentou atos para serem desenvolvidos em quatro subgrupos, nos quais boa parte dos conteúdos estava contida também no plano de Agnelo Queiroz, denotando mais uma continuidade na política do que algum tipo de ruptura (Entrevistado A; Campos, 2018).

A diferença essencial entre os planos dos dois Governos Distritais analisados não estava no conteúdo, mas na forma como foram operacionalizados. Ao mesmo tempo em que houve a distribuição de poder para os atores que estiveram coordenando cada um dos quatro subgrupos, as decisões importantes e complexas eram acompanhadas de perto pelo Governador Rollemberg (Entrevistado C). Foi 
criado pelo Governador o grupo de acompanhamento de projetos especiais, que se tornou o Escritório de Projetos Especiais (EPE), ligado à estrutura de seu gabinete (Campos, 2018). Assim, as reuniões para deliberar sobre algum tema ou forma de ação eram tidas na mesa do chefe de governo e, quando demandavam alguma intervenção, isso era realizado na mesma hora. Além de agilidade ao processo, o governador trouxe centralidade e coordenação, dando novo ritmo na execução das atividades e na liberação dos recursos:

Então a sabedoria do Governador Rollemberg foi colocar o problema no gabinete do Governador. Toda reunião o Governador estava presente e negociando; ele tem uma história com os catadores. Ao colocar em seu gabinete, ele tem as soluções, ou seja, se for necessário o governo chama o Departamento de Trânsito - Detran por exemplo e não o SLU (chamar); ele não convida o Detran, ele convoca. Se o SLU convidasse a Secretaria de Segurança Pública, a Secretaria de Estado de Desenvolvimento Humano e Social, a Secretaria de Estado de Meio Ambiente, a Agência de Fiscalização, o Departamento de Trânsito, ou seja, a gente (SLU), convida, chama e espera que as pessoas venham, mas o Governador convoca e, mesmo nessa crise econômica que o Distrito Federal está passando nesses últimos três anos, ele (Governador) priorizou recursos para viabilizar o encerramento do Lixão. Então para mim, o sucesso ou a parcela de sucesso que vai ter esse encerramento é devido a esse empoderamento que o Governador deu (...), ou seja, quando alguém me pergunta quem está fechando o Lixão, eu digo que é o Governador (Entrevistado B, p. 5).

A "tomada das rédeas" do processo de implementação pelo Governador gerou dois movimentos importantes. Primeiro, demonstrou sua preocupação com o processo de fechamento do Lixão, reservando parte significativa de seu tempo para a resolução da questão e sugerindo que aquela agenda era uma das mais importantes para o governo a ponto de ele se dedicar diretamente a ela (Senado Federal, 2015). O segundo foi a quebra com as disfunções burocráticas que emperravam o trabalho solitário das Secretarias. Com a atuação direta do Governador, houve uma celeridade nos trâmites administrativos do setor público, assim como um maior respaldo para os trabalhos desenvolvidos pelos secretários.

A centralização prevista no modelo de implementação top-down demonstrou que o Governador Rollemberg atuou de maneira a aproximar as ações realizadas com as metas estabelecidas no Plano, num movimento lógico-causal e de conformidade que funcionaria a partir do comprometimento dos implementadores (Lotta, 2019a). A lógica hierárquica imposta pelo Governador tornou o processo de implementação ágil e fez despontar a figura da autoridade pública, que se tornou importante elemento de sustentação e reforço da agenda (Bichir \& Canato, 2019), além de peça fundamental na coordenação dos atores envolvidos.

Partindo de uma lógica organizacional distinta de seu antecessor, o Governador Rollemberg atuou como pivô da política de encerramento do Lixão, reduzindo os problemas de ação coletiva e as fricções entre as agências envolvidas. Garantiu, dessa forma, a conformidade com as metas a partir do estabelecimento de estruturas, controles e canais de comunicação adequados. Os resultados apareceram de forma mais célere (Senado Federal, 2015). Não sem problemas, mas em menos de três anos do Decreto 36.437/2015 (Distrito Federal, 2015a), Brasília oficializou o fechamento do Lixão da Estrutural. 


\subsection{Da exclusão à exclusão}

A análise comparativa entre o Plano de Intervenção Técnico Político dos Resíduos Sólidos, aprovado pelo Decreto 33.445/2011 (Distrito Federal, 2011b) na gestão Agnelo Queiroz, e o Decreto 36.437/2015 (Distrito Federal, 2015a), que constituiu o grupo de trabalho para a elaboração de um Plano de Intervenção no Lixão da Estrutural na gestão Rodrigo Rollemberg, demonstrou a necessária abertura para inclusão dos catadores no processo de implementação (Barbosa, 2015; Senado Federal, 2015; GDF, 2018). Entretanto, essa inclusão foi realizada de forma passiva e na forma de apoio ao Estado (Chambers \& Kopstein, 2006).

Uma das primeiras decisões realizadas pelo Governador Rollemberg foi retomar o funcionamento do Comitê Gestor Intersetorial para Inclusão Social e Econômica de Catadores de Materiais Recicláveis do Distrito Federal - CIISC, que havia sido instituído no Governo Agnelo, mas que não havia sido implementado adequadamente. Com a retomada do CIISC, as ações direcionadas para atender os catadores foram conduzidas de maneira mais consistente. Tais atuações se deram no âmbito da assistência financeira, de ações de proteção social, de produção de capacidade técnica em associativismo e de adaptação às novas normas e rotinas de trabalho (Campos, 2018; GDF, 2018).

As entrevistas realizadas destacaram que o perfil sociocultural dos catadores foi um limitador da relação entre eles e o Estado. Havia, entre os catadores, alguns que agenciavam os próprios colegas num formato de microempresa. Garantiam a compra antecipada de produtos e revendiam mais caro, alcançando receitas maiores com menor esforço de coleta. Havia catadores que não tinham contato com trabalho em grupo, cooperativo e associativo, uma vez que sempre trabalhavam por conta própria, com seus próprios horários e rotinas. Havia ainda os que estavam no Lixão para realizar negócios, especialmente como atravessadores. Toda essa gama de atores em convívio com o Lixão carregava um perfil pouco aberto para mudanças e para propostas que os fizessem modificar os padrões de atuação que estavam estabelecidos há muito tempo naquele local. Os próprios catadores, portanto, atuaram como agentes de continuidade, e não de mudança, segundo o material de campo coletado (Entrevistado B; Entrevistado A; Campos, 2018).

Assim como o perfil sociocultural dos catadores não contribuiu para uma agenda de mudanças, segundo a voz do Governo, também é verdade que o próprio Governo não buscou construir pontes em que os catadores fossem agentes da mudança, e não exclusivamente atores passivos e com necessidades de serem amparados pelo Estado. A ausência dos catadores nos grupos de trabalho ou mesmo de espaços de participação propostos pelos Planos denuncia a forma como os catadores eram percebidos e como estavam sendo tratados (Distrito Federal, 2011b; Distrito Federal, 2015a; GDF, 2018). Forma esta diferente do que era proposto pelos relatórios técnicos encomendados pelo próprio governo do Distrito Federal (Barbosa, 2015).

O Plano de Rollemberg, assim como o de Agnelo, anos antes, previa ações para os catadores, mas não em conjunto com os catadores. Esse modelo operacional dos Planos, restrito às esferas da alta administração pública do Distrito Federal, não permitiu aos catadores estarem presentes nos ambientes de tomada de decisão. Foram agentes passivos e participantes secundários, sendo consultados 
exclusivamente por meio das "rodas de diálogos" (Campos, 2018). Não foram eles previstos para deliberar, mas para receber as decisões deliberadas em esferas que não alcançavam. Não por acaso, foi percebida uma grande quantidade de matérias jornalísticas em que a insatisfação dos catadores com as mudanças no Lixão e sua realocação para outras atividades eram o assunto principal (Campos, 2018; Correio Braziliense, 2019), assim como foi percebido em algumas entrevistas (Entrevistado A; Entrevistado C).

Não demorou muito para ocorrer os primeiros desentendimentos dentro do governo de Rollemberg em relação à forma de tratamento conferida aos catadores. Em nota, o Secretário de Meio Ambiente fez uma crítica à condução do fechamento do Lixão da Estrutural pelo fato dos catadores estarem sendo tratados como assunto marginal e pouco relevante em toda a estrutura produzida para fechar o Lixão:

O que eu alertei nesta última sexta-feira em um post publicado aqui e na minha fanpage no Facebook chegou hoje no Correio Braziliense. E não tardará a chegar em outras vias e meios de comunicação (inclusive nacionais e internacional). Por isso meus amigos no Governo, alguns dos quais muito me criticaram (e alguns com mentiras homéricas como, por exemplo, dizer que eu joguei contra o fechamento do Lixão) não adianta tampar o Sol com a peneira, negar o óbvio ou quebrar o termômetro e ignorar a febre e a inflamação. E infelizmente a maioria no Governo ligada ao assunto desprezou nossos alertas, propostas e preocupações porque falou mais alto a fotografia do fechamento do Lixão. Sim, histórico momento para o Brasil. Mas meio compromisso cumprido. Catadores não comiam lixo como maldosamente foi dito por aí por gente importante nesse Governo. Eles comem e vivem exclusivamente do que catam "do" e "no" lixo. Função que ainda poucos seres humanos valorizam, infelizmente. O Governo do Distrito Federal deu pouco com uma mão e tirou muito com a outra. Assinou contratos com algumas cooperativas que atendem economicamente uma minoria dos cooperados (catadores). Tudo bem, pode e deve aumentar quantidade e a qualidade dos contratos. Mas deu um teto (provisório) para poucos trabalharem, e tiraram quase $80 \%$ do resíduo que se transformava como que quase por milagre em pão de cada dia para mais de dois milhares de pessoas. Esse resíduo que era retirado pelos catadores em condições desumanas no Lixão (isso ninguém discorda) hoje está sendo enterrado e enchendo os cofres da empresa contratada para gerir o novo Aterro. Ou seja: o que catadores perdem, empresa ganha. (...) Digo isso porque meu pensamento é "SOCIOAMBIENTAL", não é "SÓ" ambiental. Por quê? Porque eu sou pelo fim do Lixão, sim, mas pelo fim dos catadores, não!!! (Secretário de Estado de Meio Ambiente do Distrito Federal, 2018).

Em que pesem os problemas internos dentro do núcleo estruturante do governo distrital para o fechamento do Lixão, o resultado do processo foi comemorado pelos atores governamentais e compreendido como um resultado de sucesso (Campos, 2018; Senado Federal, 2015; GDF, 2018). Para os catadores, entretanto, o sucesso foi menos aparente. Esse descontentamento foi gerado exatamente pela exclusão deles do processo participativo e dos arranjos de decisão política. A forma como foram tratados dentro do processo de fechamento esteve associada ao pensamento tido como ideal pelos gestores do Plano, que excluiu a opinião dos principais atingidos pelas mudanças: os catadores. Esse formato institucional pensado para os catadores fez com que eles criassem muita resistência à mudança, para além de seu perfil avesso às transformações. As reclamações passavam pelos argumentos de que muitos catadores não foram alocados no novo ambiente de coleta (galpões), de que a distância entre moradia e galpões era grande, fazendo com que os 
recursos ganhos no trabalho fossem consumidos com o translado, a própria atividade de separação dos resíduos sólidos tinha diminuído, o que gerava ganhos menores (Agência Brasil, 2018). Muitos noticiários creditaram, em parte, o aumento dos moradores de rua no Distrito Federal, chegando a 3 mil no início de 2019, como reflexo do descontentamento dos catadores com as novas condições de trabalho e remuneração (Correio Braziliense, 2018).

Casos semelhantes de resistência e de exclusão de catadores foram observados em pesquisas de Pellow (2004; 2007), em dezesseis casos de conflitos em aterros sanitários mapeados por Porto et al. (2013) e em Jacobi \& Besen (2011).

A exclusão dos catadores do processo de tomada de decisão sobre o fechamento do Lixão aprofundou a vulnerabilidade do grupo e foi na contramão do que prevê a Política Nacional de Resíduos Sólidos (Severi, 2009; Brasil, 2010). Ainda que ajustes em prol dos catadores venham sendo percebidos ao longo do tempo - disponibilidade de ônibus para translado, seguridade social, aumento da quantidade de galpões, melhoria da remuneração -, essas ações ainda não abrangem a totalidade dos catadores (Senado Federal, 2015). O que marca o processo de encerramento do Lixão, portanto, é o formato pouco inclusivo dos atores não governamentais, em especial, dos catadores, característica percebida durante a produção desse trabalho.

Nesse sentido, a relação entre Governo e catadores aparentou não possuir nenhuma relação com a tentativa de empoderamento da sociedade civil (Bortoli, 2009), mas sobremaneira, a busca por um Estado mais ágil, flexível e efetivo. A sociedade, dessa forma, foi parte de um processo de filantropização e de caridade que não envolvia a construção de cidadania, de aspectos cívicos, de redistribuição de poder e de responsabilidades (Nogueira, 2011). Nesse sentido, a insuficiente participação da sociedade civil produziu movimentos de maximização de interesses de grupos específicos, o chamado rent-seeking, e de despolitização do coletivo, conforme relatado na fala do Secretário de Meio Ambiente. Caracterizou-se, assim, uma sociedade civil fora do Estado (Gohn, 1997). O que se evidenciou, portanto, é a relação entre Estado e sociedade civil distante do que Chambers \& Kopstein (2006) nomearam de dialógica, com rotinas de interação bloqueadas para a participação institucionalizada. Por isso, observou-se uma relação de oposição entre sociedade civil e Estado na forma de protestos e não aceitação, por parte dos catadores, da nova situação que se impôs.

\section{Considerações finais}

Na gestão dos governos analisados - Agnelo Queiroz (2010 - 2014) e Rodrigo Rollemberg (2014 -2018) - verificou-se que os Planos de Intervenção voltados para o controle dos resíduos sólidos demarcaram políticas públicas que seguiram escopos semelhantes, em que se propunha a remodelação do sistema de gestão dos resíduos sólidos no Distrito Federal. Isso posto, cabe destacar que, na gestão do governador Agnelo Queiroz, o Plano de Intervenção Técnico Político dos resíduos sólidos possuiu uma abrangência maior na questão do gerenciamento de tais resíduos pelo governo. Essa abrangência necessitou de maior descentralização do direcionamento de ações decorrentes do Plano aos órgãos envolvidos na sua atuação. A descentralização neste período previa decisões autônomas das Secretarias de Estado em que existiu uma aproximação 
ao modelo de implementação botton-up e menor participação do governador na tomada de decisão e coordenação das ações. Os resultados mostraram que a ausência do governador como ator-chave nos processos decisórios inviabilizou diversas ações que padeceram por morosidade e falta de recursos.

Já no Plano de Intervenção no Lixão da Estrutural implementado durante a gestão do governador Rodrigo Rollemberg houve, como indica o nome do Plano, ênfase para o Lixão da Estrutural, direcionando as ações para o seu fechamento e encaminhamento dos resíduos sólidos para o novo aterro. Durante a gestão do Governador Rollemberg, a tomada de decisão foi realizada a partir das determinações advindas do próprio chefe distrital, sendo que as Secretarias relevantes para a implementação atuaram como operacionalizadoras das determinações do Governador. A criação do Escritório de Projetos Especiais, subordinado ao gabinete do Governador, demonstrou a importância dada por Rollemberg para a concretização do fechamento do Lixão. As decisões centralizadas e pensadas de forma lógico-linear demonstraram o entendimento de que o fechamento do Lixão era um problema de gestão, e que novos desenhos operacionais seriam necessários e suficientes para encerrar de suas atividades. De fato, esse pensamento resolveu as questões de destinação dos resíduos sólidos na capital ao encerrar as atividades do Lixão em 2018, tornando-o um aterro controlado (Senado Federal, 2015).

A questão sobre a participação dos catadores na implementação de políticas no Governo de Agnelo Queiroz foi percebida a partir da inclusão das cooperativas e associações no desenho do Plano de Intervenção Técnico Político. O plano previa a contratação dos cooperados e associados para o Programa de coleta seletiva, mas não na tomada de decisão política. Na gestão Rollemberg o cenário se manteve e a exclusão dos catadores ficou evidente. Ainda que houvesse instrumentos previstos nos Planos de fechamento para lidar com os catadores, o próprio entendimento das necessidades desse grupo de cidadãos foi produzido autoritariamente, sem diálogo ou outra forma de inclusão deles como atores empoderados e capazes de influenciar as ações do Estado. Dada a construção passiva da parceria entre os catadores e o Estado, os catadores passaram a constituir uma barreira de mudança e se transformaram nos principais críticos ao fechamento do Lixão.

O fechamento do Lixão ocorrido em janeiro de 2018, entretanto, não expõe um cenário isolado de sucesso da política pública. Ainda que no discurso político-institucional o Lixão da Estrutural tenha sido fechado, o tema requer distanciamento temporal para ser estudado e discutido. As questões socioeconômicas que envolvem os catadores (assistência pública de seguridade social, garantias fundamentais de saúde, assim como os direitos trabalhistas) e a questão da educação ambiental na separação dos resíduos sólidos pela população não estão esgotadas e, portanto, resolvidas em definitivo. Há, em adição, o surgimento de novos temas, como o futuro do novo aterro sanitário, os impactos desse novo aterro na população local, o restauro da área do Lixão da Estrutural (já transformado em um aterro controlado, mas sem recuperação ambiental completa (Metrópoles, 2019; MPDFT, 2019) e a reflexão de como enxergar os resíduos sólidos como agente socioeconômico, isto é, como instrumento de inclusão social no Brasil e, em particular, no Distrito Federal. Nesse sentido, uma agenda de pesquisa parece conveniente. Sugerimos alguns pontos: 
a) Implementação: aprofundar a análise dos determinantes de implementação das políticas de encerramento de aterros sanitários em outros municípios brasileiros. Buscar a compilação de fatores que facilitam e/ou prejudicam a implementação no sentido de contribuir para uma teoria mais sólida de implementação de políticas públicas em situações de problemas complexos (wicked problems) e em âmbito nacional, buscando penetrar no debate já existente (IPEA, 2012; Moraes, 2012; Heber \& Silva, 2014; Besen et al., 2017; Campos, 2018; Maiello et al., 2018).

b) Participação: pesquisar outros casos de encerramento de aterros sanitários pelo Brasil, especialmente após a Política Nacional de Resíduos Sólidos de 2010, e analisar como (ou se) está ocorrendo a participação dos catadores nesses processos decisórios e o formato e a dinâmica dessa participação. Utilizar metodologias que observem a opinião dos próprios catadores. Aproximar as discussões de participação com os instrumentos de participação previstos na Política Nacional de Resíduos Sólidos e dialogar com a literatura existente (Bortoli, 2009; Bringhenti \& Gunther, 2011; Jacobi \& Besen, 2011; Severi, 2014; Lima et al., 2017).

c) Política Nacional de Resíduos Sólidos: produzir análises que visem a entender os motivos para o baixo grau de implementação da Política Nacional de Resíduos Sólidos no Brasil. Atentar para dinâmicas institucionais, governança de políticas públicas, participação e coprodução, arranjos cooperativos e federativos de compartilhamento de responsabilidades, dentre outros. Pesquisar comparativamente casos de sucesso e de fracassos para entender as variáveis explicativas dos resultados.

\section{Referências}

Abranches, S. A Era do Imprevisto: a grande transição do século XXI. Rio de Janeiro: Companhia das Letras, 2017.

ADASA - Agência Reguladora de Água, Energia e Saneamento Básico do Distrito Federal. Relatório Anual de Atividades. Distrito Federal: Adasa, 2017.

ABRELPE - Associação Brasileira de Empresas de Limpeza Pública e Resíduos Especiais. Panorama dos Resíduos Sólidos no Brasil 2017. São Paulo: Abrelpe, 2017.

Abers, R.; Bulow, M. Social Movements and the State: conventional and Contentious Politics. In: Ames, B. (Org.). Routledge Handbook of Brazilian Politics. London: Routledge, p. 105-118, 2019.

Agência Brasil. Lixão de Brasília é Fechado; Catadores Criticam Transferência para Galpões, 2018. Disponível em: <http://agenciabrasil.ebc.com.br/geral/noticia/2018-01/ lixao-de-brasilia-e-fechado-catadores-criticam-transferencia-para-galpoes>. Acesso em: fev. 2018.

Avritzer, L. Participatory Institutions: the production of institutional success and Efficiency. In: Ames, B. (Org.). Routledge Handbook of Brazilian Politics. London: Routledge, p. 331-338, 2019.

Axelrod, R.; Hamilton, W. D. The evolution of cooperation. Science, 211(4489), 1390-1396, 1981. doi: 10.1126/ science.7466396

Azevedo, A. L.; Gomes, R. C. Discurso e Poder na Formulação de Políticas Públicas Ambientais: o Caso da Política Nacional de Resíduos Sólidos. Desenvolvimento em Questão, 16(44), 133-167, 2018. doi: 10.21527/22376453.2018.44.133-167

Barbosa, I. A. Elaboração de Estudo em Regulação de Recursos Hidricos e Saneamento - Contrato: SA-1756/2015, 2015. Disponível em: $<$ http://www.slu.df.gov.br/wp-content/uploads/2017/12/regulacao_p3.pdf $>$. Acesso em: mar. 2018.

Besen, G. R.; Freitas, L.; Jacobi, P.R. (Org.). Política Nacional de Resíduos Sólidos: implementação e monitoramento de resíduos urbanos. São Paulo: IEE USP; OPNRS, 2017. 
Bichir, R.; Canato, P. Solucionando Problemas Complexos? Desafios de implementação de políticas intersetoriais. In: Pires, R. (Org.). Implementando Desigualdades: reprodução de desigualdades na implementação de políticas públicas. Brasília: ENAP, p. 243-266, 2019.

Birkland, T. An introduction to the policy process: theories, concepts, and models of public policy making. UK: Routledge, 2015.

Bortoli, M. A. Catadores de Materiais Recicláveis: a construção de novos sujeitos políticos. Revista Katálysis, 12, 105-114, 2009.

Brasil. Constituição da República Federativa do Brasil: texto constitucional promulgado em 5 de outubro de 1988, com as alterações determinadas pelas Emendas Constitucionais. Brasília: Senado Federal, 2016.

Brasil. Lei 12.305, de 2 de agosto de 2010. Institui a Política Nacional de Resíduos Sólidos. DOU de 03/08/2010.

Bringhenti, J. R.; Günther, W. M. R. Participação Social em Programas de Coleta Seletiva de Resíduos Sólidos Urbanos. Engenharia Sanitária e Ambiental, 16, 421-430, 2011.

Campos, H. K. Como Fechamos o Segundo maior Lixão do Mundo. Revista Brasileira de Planejamento e Orçamento, 8 (2), 204-253, 2018. Disponível em: assecor.org.br/files/3015/4470/2872/como_fechamos_o_segundo_maior_liX_o_do_mundo_.pdf.

Canovan, M. The People. In: Dryzek, J.; Honing, B.; Phillips, A. The Oxford Handbook of Political Theory. UK: Oxford University Press, p. 349-362, 2006.

Chambers, S.; Kopstein, J. Civil Society and the State. In: Dryzek, J.; Honing, B.; Phillips, A. (Org.). The Oxford Handbook of Political Theory. UK: Oxford University Press, p.363-381, 2006.

Coelho, S. P.; Favareto, A. Dilemas da participação e desenvolvimento territorial. RDE-Revista de Desenvolvimento Econômico, 10, 15-26, 2010.

Correio Braziliense. Brasilia se Torna a Terceira Maior Capital do País, com 3 mi de Habitantes, 2017. Disponível em: < https://www.correiobraziliense.com.br/app/noticia/ cidades/2017/08/31/interna_cidadesdf,622269/brasilia- se-torna-a-terceira-maior-capital-do-pais-com-3-mi-dehabita.shtml> Acesso em: dez. 2018.

Correio Braziliense. Após um mês do Fechamento do Lixão, Catadores vão às Ruas Atrás de Sustento, 2018. Disponível em: < https://www.correiobraziliense.com.br/app/noticia/ cidades/2018/02/18/interna_cidadesdf,660543/apos-ummes-do-fechamento-do-lixao-catadores-vao-as-ruas-atrasde-sus.shtml>. Acesso em: dez. 2018.

Correio Braziliense. Catadores ainda Tentam se Firmar após Fechamento do Lixão da Estrutural, 2019. Disponível em: <https://www.correiobraziliense.com.br/app/noticia/ cidades/2019/01/20/interna_cidadesdf,731621/catadorestentam-se-firmar-apos-fechamento-do-lixao-da-estrutura. shtml>. Acesso em: mar. 2019.

Dagnino, E. Sociedade Civil e Espaços Públicos no Brasil. Campinas: Paz e Terra, 2002.

Denzin, N. K.; Lincoln, S. Y. The Sage handbook of qualitative research. NY: Sage, 2017.

Distrito Federal. Decreto 32.922, de 11 de maio de 2011. Institui o Comitê Intersetorial. Brasília: DODF n ${ }^{\circ} 89$ de 11/05/2011a.

Distrito Federal. Decreto 33.445, de 26 de dezembro de 2011. Plano de Intervenção Técnico Político de Gestão dos Resíduos Sólidos no DF. Brasília: DODF n ${ }^{\circ} 246$ de 26/12/2011b.

Distrito Federal. Decreto 36.437, de 2 de abril de 2015. Institui Grupo de Trabalho. DODF n ${ }^{\circ} 66$ de 06/04/2015a.

Distrito Federal. Decreto 36.528, de 1 de junho de 2015. Declara Situação de Emergência e de Perigo no Âmbito da Limpeza Pública do Distrito Federal. DODF no 104 de 29/05/2015b.

Domiciano, M.; Capelari, M. G. M.; Queiroz, L. F. The Closure Trajectory of the Largest Landfill in Latin America: within centralization, decentralization and exclusion. In: Anais da International Conference in Public Policy. Montreal/CA, out., 2019.

Evans, P. Collective capabilities, culture, and Amartya Sen's Development as Freedom. Studies in comparative international development, 37(2), 54-60, 2002. doi: 10.1007/ BF02686261 
Evans, P. Além da monocultura institucional: instituições, capacidade e o desenvolvimento deliberativo. Sociologias, 5(9), 20-63, 2003. doi: 10.1590/S1517-45222003000100003

Evans, P. The Capability Enhancing Developmental State: Concepts and National Trajectories. In: Kim, E. M.; Kim, P. H. (Org.). The South Korean Development Experience. Critical Studies of the Asia Pacific Series. UK: Palgrave Macmillan, p. 83-110, 2014.

Gaventa, J.; Barret, G. So what difference does it make? Mapping the outcomes of citizen engagement. In: Anais do IDS Working Papers. Brighton, Outubro, 2010. Disponível em: <https://gsdrc.org/document-library/so-whatdifference-does-it-make-mapping-the-outcomes-of-citizenengagement/>. Acesso em: jul. 2019

Gerring, J. Case study research: principles and practices. USA: Cambridge University Press, 2017.

Gohn, M. C. Teoria dos Movimentos Sociais: paradigmas clássicos e contemporâneos. São Paulo: Loyola, 1997.

GDF. Governo do Distrito Federal. Programa Brasília Sustentável II. Brasília: GDF, 2009. Disponível em: <http:// www.adasa.df.gov.br/images/stories/anexos/licitacoes/ brasiliaSustentavel/bsbConc04-2012/RAA_Relat_Aval_ Amb_PBSB.pdf $>$. Acesso em: fev. 2018.

GDF. Governo do Distrito Federal. Relatório sobre a Situação de Emergência no Âmbito da Limpeza Urbana Jóquei. Brasília: GDF, 2015a. Disponível em: <http://www.slu.df. gov.br/wp-content/uploads/2017/12/relatorio_crise_lixao. pdf $>$. Acesso em: fev. 2018

GDF. Governo do Distrito Federal. Plano de Intervenção Lixão do Jóquei. Brasília: GDF, 2015b. Disponível em: $<$ http://www.slu.df.gov.br/wp-content/uploads/2017/12/ plano_intervencao.pdf $>$. Acesso em: jan. 2018.

GDF. Governo do Distrito Federal. Plano Distrital de Gestão Integrada de Resíduos Sólidos. Brasília: GDF, 2018. Disponível em: <http://www.so.df.gov.br/wp-conteudo/ uploads/2018/03/PDGIRS.pdf $>$. Acesso em: dez. 2018.

Heber, F.; Silva, E. M. D. Institucionalização da Política Nacional de Resíduos Sólidos: dilemas e constrangimentos na Região Metropolitana de Aracaju (SE). Revista de Administração Pública - RAP, 48, 913-937, 2014.
Hochstetler, K.; Keck, M. E. Greening Brazil: Environmental activism in state and society. USA: Duke University Press, 2007.

IPEA. Instituto de Pesquisa Econômica Aplicada. Diagnóstico dos resíduos sólidos urbanos. Relatório de pesquisa. Brasília: IPEA, 2012.

Jacobi, P. R.; Besen, G. R. Gestão de Resíduos Sólidos em São Paulo: desafios da sustentabilidade. Estudos Avançados, 25, 135-158, 2011.

Lascoumes, P.; Le Gales, P. A ação pública abordada pelos seus instrumentos. Revista Pós ciências sociais, 9(18), 1944, 2012. Disponível em: periodicoseletronicos.ufma.br/ index.php/rpcsoc/article/view/1331/1048

Lima, L.; D’Aascenzi, L. Implementação de Políticas Públicas: perspectivas analíticas. Revista de Sociologia e Politicas, 21(48), 101-110, 2013. doi: 10.1590/S010444782013000400006

Lima, D. R.; Simões, A. F.; Mercedes, S. S. Eventos públicos, ganhos privados: limpeza urbana e gerenciamento de resíduos sólidos urbanos (RSU) no renascimento do Carnaval de rua paulistano. Desenvolvimento e Meio Ambiente, 42, 242-240, 2017.

Lipsky, M. Street-Level Bureaucracy, Dilemmas of the Individual in Public Services. New York: Russell Sage Foundation, 2010.

Lotta G. S. Implementation of Public Policy, Brazil. In: Farazmand, A. (Org.). Global Encyclopedia of Public Administration, Public Policy, and Governance. USA: Springer; Cham., 2019a.

Lotta, G. S. Teorias e análises sobre implementação de políticas públicas no Brasil. Brasília: ENAP, $2019 \mathrm{~b}$.

Maiello, A.; Britto, A. L. N.; Valle, T. F. Implementação da Política Nacional de Resíduos Sólidos. Revista de Administração Pública-RAP, 52, 24-51, 2018.

Margetts, H.; Hood, C. (Org.). Paradoxes of modernization: unintended consequences of public policy reform. UK: Oxford University Press, 2012.

Marulanda, N. R.; Velarde, J. C.; Sulbrandt, J.; Navar- 
rete, N.; Piergentili, N.; Gaetani, F. Entre el diseño y la evaluación: el papel crucial de la implementación de los programas sociales. Banco Interamericano de Desarrollo (BID). Washington: BID, 2007.

Mazmanian, D.; Sabatier, P. Implementation and Public Policy. USA: University Press of America, 1989.

Metrópoles. Sem recuperação ambiental, fechamento do lixão completa um ano e meio. 2019. Disponível em: $<$ https:// www.metropoles.com/distrito-federal/sem-recuperacao-ambiental-fechamento-do-lixao-completa-um-ano-e-meio $>$. Acesso em: jul. 2019.

Moraes, J. L. D. Os consórcios públicos e a gestão integrada de resíduos sólidos em pequenos municípios do estado do Ceará, Brasil. Revista Geonorte, 3, 1171-1180, 2012.

MPDFT. Ministério Público do Distrito Federal e Territórios. Vistoria no Lixão da Estrutural: MP cobra política ambiental para descarte de lixo, 2019. Disponível em: https:// www.mpdft.mp.br/portal/index.php/comunicacao-menu/ sala-de-imprensa/noticias/noticias-2019/11288-vistoria-no-lixao-da-estrutural-mp-cobra-politica-ambiental-para-o-descarte-de-lixo . Acesso em: mai. 2020

Nogueira, M. A. Um estado para a Sociedade Civil: temas éticos e políticos da gestão democrática. São Paulo: Cortez, 2011.

Nogueira, M. A. Representação, Crise e Mal-Estar Institucional. Sociedade e Estado, 1(29), 91-111, 2014. doi:10.1590/S0102-69922014000100006

Olson, M. The logic of collective action (v. 124). USA: Harvard University Press., 2009.

Ostrom, E. Governing the commons: the evolution of institutions for collective action. USA: Cambridge University Press, 2014.

Padilha, N. S. Fundamentos constitucionais do direito ambiental brasileiro. São Paulo: Elsevier, 2010.

Pellow, D. N. Garbage wars: the struggle for environmental justice in Chicago. USA: MIT Press, 2004.

Pellow, D. N. Resisting global toxics: transnational movements for environmental justice. USA: MIT Press, 2007.
Pires, R. Estilos de implementação e resultados de políticas públicas: fiscais do trabalho e o cumprimento da lei trabalhista no Brasil. Dados, 52(3), 734-769, 2009. doi: 10.1590/ S0011-52582009000300006

Pires, R.; Gomide, A. Capacidades estatais e democracia: a abordagem dos arranjos institucionais para análise de políticas públicas. In: Pires, R.; Gomide, A. Capacidades estatais e democracia: arranjos institucionais de políticas públicas. Brasília: IPEA, p. 15-30, 2014.

Portal G1. Catadores Fecham Lixão da Estrutural, no DF, após Morte de Trabalhador. Disponível em: $<$ http:// g1.globo.com/distrito-federal/noticia/2014/04/catadores-fecham-lixao-da-estrututal-no-df-apos-morte-de-trabalhador. html>. Acesso em: dez. 2018.

Porto, M. F.; Pacheco, T.; Leroy, J. P. Injustiça ambiental e saúde no Brasil: o mapa de conflitos. Rio de Janeiro: Editora Fiocruz, 2013.

Presmman, J.; Wildvsky, A. Implementation. Berkeley: University of California Press, 1984.

Ribot, J. C. Representation, citizenship and the public domain in democratic decentralization. Development, 50(1), 43-49,2007. doi: 10.1057/palgrave.development.1100335

Sabatier, P. Top-down and bottom-up approaches to implementation research: a critical analysis and suggested synthesis. Journal of Public Policy, 6(1), 21-48, 1986.

Secretário de Estado de Meio Ambiente do Distrito Federal. Nota sobre o processo de encerramento do Lixão da Estrutural, 2018. Disponível em: https://web.facebook.com/ alimaDF . Acesso em: dez. 2018.

Senado Federal. Audiência Pública da Comissão de Desenvolvimento Regional e Turismo de 05/11/2015. Brasília: Senado Federal, 2015. Disponível em: http://legis.senado. leg.br/escriba-servicosweb/reuniao/pdf/4176 . Acesso em: fev. 2018

Severi, F. C. Os Catadores de Materiais Recicláveis e Reutilizáveis na Política Nacional de Resíduos Sólidos. Revista Direito e Práxis, 5, 152-171, 2009.

Silva, S. M. Participation in Public Policy: Brazil. In: 
Farazmand, A. (Org.). Global Encyclopedia of Public Administration, Public Policy, and Governance. USA: Springer, Cham., p.1-10, 2019.

SLU - Serviço de Limpeza Urbana. Relatório dos Serviços de Limpeza Urbana e Manejo dos Resíduos Sólidos do Distrito Federal. Brasília: SLU, 2016. Disponível em:<www. slu.df.gov.br>. Acesso em: set. 2018.

Souza, C. Coordenação de políticas públicas. Brasília: ENAP, 2018.

Teixeira, A. C.; Tatagiba, L.; Romão, W. Conselhos: onde Bolsonaro vê burocracia, há democracia. Portal de Notícias, UOL, 2019.

Tummers, L. The relationship between coping and job performance. Journal of Public Administration Research and Theory, 27(1), 150-162, 2017. doi: 10.1093/jopart/muw058
Urban, T. Missão (quase) impossível: aventuras e desventuras do movimento ambientalista no Brasil. Rio de Janeiro: Editora Petrópolis, 2001.

Viola, E. J. O movimento ecológico no Brasil, 1974-1986: do ambientalismo à ecopolítico. Florianópolis: Editora da UFSC, 1987

Weible, C.; Sabatier, P. Theories of the Policy Process. UK: Routledge, 2017.

Wu, X.; Ramesh, M.; Howlett, M.; Fritzen, S. The Public Policy Primer: managing the policy process. UK: Routledge, 2018.

Yin, R. K. Case study research and applications: design and methods. UK: Sage Publications, 2017. 